\title{
The mechanical properties of thin alumina films deposited by metal-organic chemical vapour deposition
}

\author{
V. A. C. Haanappel, D. v. d. Vendel, H. S. C. Metselaar, H. D. van Corbach, T. Fransen*, \\ P. J. Gellings \\ Department of Chemical Technology, University of Twente, P.O. Box 217. 7500 AE Enschede, Netherlands
}

Received 11 February 1994; accepted 16 June 1994

\begin{abstract}
Amorphous alumina films were deposited by metal--organic chemical vapour deposition (MOCVD) on stainless steel, type AISI 304. The MOCVD experiments were performed in nitrogen at low and atmospheric pressures. The effects of deposition temperature, growth rate and film thickness on the mechanical properties have been studied.

The experiments were performed with the dynamic ultra-micro-hardness tester, DUH-200, and the scanning scratch tester, SSI-1)I, both developed by Shimadzu. The DUH-200 is associated with crack formation during indentation. This technique involves a qualitative method to study the crack behaviour of the thin alumina films as well as a method to estimate the fracture toughness of the film and the film/substrate interface. The experiments performed with the SST-101 are based on the estimation of the film adhesion to the substrate by determining a critical load; the load where the film starts to spall or to delaminate.

The best mechanical properties were obtained using low deposition rates and high deposition temperatures. Therefore, low-pressure MOCVD is recommended in addition to the deposition of alumina films at high temperatures.
\end{abstract}

Keywerds: Aluminium oxide; Chemical vapour deposition: Coatings; Organometallic vapour deposition

\section{Introduction}

The protection of several materials against environmental attack is generally related to the presence of adherent and protective coatings. These coatings should be incrt in aggressive environments. Oxide scales, such as alumina or silica, have shown a sufficient chemical resistance against aggressive compounds [1,2]. Besides the clemical properties, the mechanical properties are also of considerable importance $[3,4]$. At present, there is an increasing interest in using indentation and scratch test techniques to study mechanical properties, such as the adhesion strength of thin oxide films to the substrate [2,5-21].

The mechanical properties measured most frequently by the indentation technique are the hardness and Young's modulus. In conventional micro-hardness tests, which have been in use for many years, the contact area is determined optically (measuring the diagonal length). Using depth-sensing instruments,

* Corresponding author. which have recently become more common, the hardness data can be obtained without imaging the indentation, saving time and providing improved repeatability [6]. Doerner and Nix [6] described the calculation of several hardness values from load-displacement curves. From the data obtained, the hardness can be calculated using the maximum depth at peak load, the final depth (the residual depth of the impression after final loading) and the plastic depth determined as the unloading intercept. These authors showed that the results obtained from measured areas agree well with the hardness calculated from the plastic depth, whereas Oliver and Pharr [7] reported that the final depth gives a better estimate of the contact area than the depth at peak load (calculated from the maximum depth). This means that the error in hardness value from plastic or final depth is much smaller than from the maximum depth. From the experimentally measured stiffness obtained from the upper portion of the unloading curve, the elastic modulus can be calculated $[3,4,7]$.

Besides indentation experiments on bulk materials, micro-hardness tests of thin films and surface layers on 
a substrate also become important. The major problem associated with indentation tests of thin films is the indentation depth: the underlying substrate can affect the indentation measurements. Only thick films or very small indentations will give true hardness values of the film without detectable influence from the substrate. It is generally accepted that the ratio of the coating thickness $t$ to the indention depth $h$ should be larger than ten [22] in order to obtain hardness values not affected by the underlying substrate. Manika and Maniks [22] studied the critical $t / h$ values for many coatings over a wide range of layer/substrate hardness ratios. Reliable film propertics were only obtained when the ratio of the indentation depth to the film thickness did not exceed a critical value, approximately between 0.07 and 0.2 . When the ratio $t / h$ exceeds the critical value, the hardness is no longer a characteristic of the coating alone, since it is also influenced by the substrate material.

Several methods have been developed to quantify the hardness of the film from the composite hardness. Jönnson and Hogmark [8] derived a simple equation where the composite hardness is expressed as a mean of the film and substrate hardnesses. An almost identical expression was derived by Bückle [23]. Other simple models for determining the hardness of thin coatings were reported by Thomas [9], based on a simple cmpirical relationship between the measured hardness and the indentation diagonal, and by Burnett and Page [24], based on a volume law of mixtures. Calculations of the Young's modulus from the slope of the unloading curve with a significant effect from the substrate were performed empirically by Doerner and Nix [6].

The indentation instrument can be used not only to determine the hardness, the elastic modulus and the elastic and plastic properties, but also as an analytical technique to measure the coating adhesion [9]. It is known that the indenter imposes high stresses on the coating/substrate interface close to the edges of the impression. Poor adhesion can result in spalling or delamination of the coating. This phenomenon can be used, as reported by Thomas [9], as a qualitative test on coated components. Micro-indentation as a technique for determining adhesion properties (film cracking associated with indentation) was also used by, amongst others, Samandi et al. [10] and Wu et al. [11]. Samandi et al. [10] studied the influence of the film thickness on the hardness, elastic modulus and critical load for fracturing of thin silica films on ductile substrates. Wu et al. [11] investigated the adhesion of carbon films on silicon substrates by micro-indentation and micro-scratch tests.

Another technique available to characterize the adhesion strength of thin films on a substrate is the scratch test, which is increasingly used in the coating industry. The test consists of drawing a diamond stylus with a known radius over a coating with increasing vertical loads. The mechanical resistance of the coating/sub- strate interface is characterized by a critical load which is the minimum load at which cracking or delamination of the coating can be observed. The resultant scratch can also be observed by optical means in order to estimate the minimum load at which the film was damaged by a lack of adhesion.

Besides the determination of adhesion, a friction modulus can also be determined from the scratch adhesion tests [25]. The calculation of the friction modulus is based on reading the inclination of the absolute value curve of the load-cartridge output oblained. When a diamond stylus is used, the friction modulus is obtained by comparing the friction value of the test piece with that of diamond.

In this study, experiments were performed to obtain some understanding of the adhesion characteristics of thin alumina films on AISI 304, deposited by low- and atmospheric-pressure metal-organic chemical vapour deposition. Micro-indentation and scanning scratch tests were used to evaluate the adhesion properties. The adhesion properties were determined as a function of the coating thickness, the post-deposition thermal treatment, and the deposition temperature.

\section{Experimental details}

\subsection{Preparation of the samples}

Depositions were performed on stainless steel, type AISI $304(18 \% \mathrm{Cr}, 8 \% \mathrm{Ni}, 0.08 \% \mathrm{C}, 1 \% \mathrm{Si}, 2 \% \mathrm{Mn}$, $71 \% \mathrm{Fe}$ ). The AISI 304 samples (discs of 12 and $20 \mathrm{~mm}$ diameter with $1 \mathrm{~mm}$ thickness) were ground on $\mathrm{SiC}$ paper with a final size of 4000 grit, followed by a polishing treatment with $\mathrm{Al}_{2} \mathrm{O}_{3}(3 \mu \mathrm{m})$, and subsequently cleaned ultrasonically for $30 \mathrm{~min}$ in soap, hexane and ethanol. Finally, the samples were immersed in Struer's etching fluid ( $5 \%$ solution of $3 \mathrm{M}$ nitric acid in cthanol) for $15 \mathrm{~min}$, washed with pure ethanol and dried in hot air.

\subsection{Low-pressure $\mathrm{MOCVD}$ of $\mathrm{Al}_{2} \mathrm{O}_{3}$}

The $\mathrm{Al}_{2} \mathrm{O}_{3}$ coatings were deposited by pyrolysis of ATSB (Janssen Chimica) in a LPCVD system, as shown in Fig. 1. It consists of a horizontal quartz tube reactor $(134 \mathrm{~cm}$ long, $10 \mathrm{~cm}$ in diameter) in a threezone furnace (Tempress model Omega Junior). A stream of pure nitrogen gas (Praxair nitrogen 5.0) passed through the ATSB precursor in a silicone oil bath. The ATSB has a vapour pressure of $0.133 \mathrm{kPa}$ ( 1 torr) at $138{ }^{\circ} \mathrm{C}$. This saturated gas was diluted with pure nitrogen gas before entering the reactor. The gas line between the ATSB container and the reactor was heated to $150^{\circ} \mathrm{C}$ to prevent condensation of the precursor. All gas streams were controlled by electronic mass- 


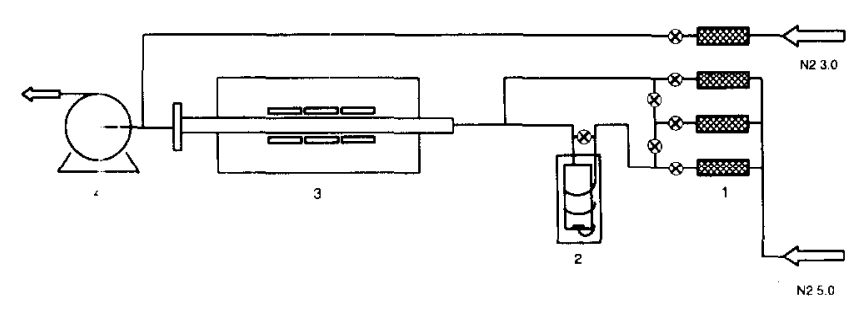

Fig. I Schematic view of the M O LPCVD reactor: 1, mass-flow controllers: 2. container with ATSB at constant temperature; 3. three-i one furnace: 4 , vacuum pump.

flow controllers (Brooks 5850TR). The linear gas velocity in the reactor was $2.6 \mathrm{~m} \mathrm{~s}^{-1}$. The deposition temperature was monitored by three thermocouples which extended into the reactor below the specimens. The emperature profile was maintained as constant as possible $( \pm 0.5 \mathrm{C})$ over the length of the specimen load. The reactor pressure during deposition was monitored by capacitive pressure sensors (MKS Baratron type 122A) and kept at the desired value by adding an excess flow of nitrogen to the vacuum pump (Leybold D65BCS). Standard conditions were: deposition temperature, $280 \mathrm{C}$; partial pressure of ATSB, $9.3 \times 10^{-4}$ $\mathrm{kPa}$ (ATSB saturation temperature, $138^{\circ} \mathrm{C}$ ); reactor pressure. $0.17 \mathrm{kPa}$; and film thickness, $0.5 \mu \mathrm{m}$.

\subsection{Atmospheric-pressure $\mathrm{MOCVD}$ of $\mathrm{Al}_{2} \mathrm{O}_{3}$}

A schematic diagram of the experimental set-up was show $n$ in a previous paper [26]. The ATSB was introduced into the furnace by passing nitrogen gas through the ATSB bubbler with an equilibrium vapour pressure of ATSB at $138 \mathrm{C}$ of $0.13 \mathrm{kPa}(1.0 \mathrm{~mm} \mathrm{Hg})$. The ATSB concentration was adjusted by controlling the flux of nitrogen gas through the ATSB bubbler at atmospheric pressure. This gas mixture was added to the main nitrogen flow which entered the reaction chamber. The flow rates were controlled by mass-flow controllers (Brooks type 5850TR). The deposition reaction was carried out in a quartz tube with a diameter of $45 \mathrm{~mm}$. The uniform temperature zone in the reactor is $120 \mathrm{~mm}$. The specimens were attached to a ceramic tube parallel to the gas flow, with a thermocouple inside in order to measure the substrate temperature and cont:ol the furnace temperature.

The deposition rate of the films deposited by atmospheric- and low-pressure MOCVD on the metallic subs rate was determined by weighing the samples before and after the deposition. Standard conditions were: depcsition temperature, $330 \mathrm{C}$; partial pressure of ATSB. $0.026 \mathrm{kPa}$ (ATSB saturation temperature, 138 C); and film thickness, $0.5 \mu \mathrm{m}$.

\subsection{The dynamic ultra-micro-hardness tester}

The hardness tester DUH-200 developed by Shimad $z u$ is a testing device suitable for providing data on

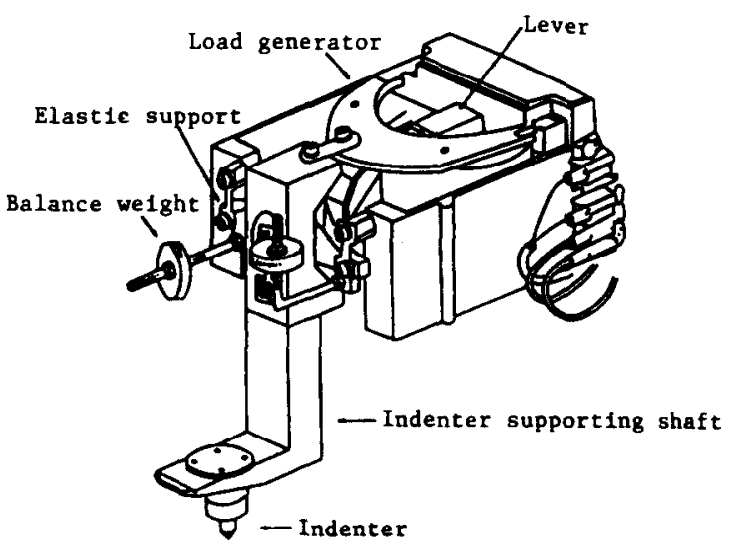

Fig. 2. Outline of the loading unit of the micro-hardness tester.

strength characteristics of a wide range of materials. The DUH-200 evaluates the conventional and the dynamic hardness of the test specimen. The dynamic hardness in the indentation process is based on both plastic and elastic deformation, whereas the conventional hardness is based on the plastic deformation alone by measuring the indentation depth after removing the load. The main unit comprises a hardness tester main unit, a test-piece stage ( $X-Y$ stage), and an automatic measurement control unit.

The operating principle of the DUH-200 employs two different techniques: one is the low-loading method, which utilizes electromagnetic forces, and the other is the measurement of the indentation depth using a differential transformer. The loading system, as shown in Fig. 2, consists of a load generator, a lever, an elastic support, a balance weight and an indenter. The load generator utilizes the electromagnetic loading method to enable low loading of $9.8 \times 10^{-5} \mathrm{~N}(10$ mgf). The load generator contains a mechanism using an elastic support to ensure that the load is applied in the vertical direction.

The major specifications of the Shimadzu Dynamic Ultra Micro Hardness Tester DUH-200 are: loading method. electromagnetic coil; load range, 0.01 gf to 200 gf; indentation depth measuring method, differential transformer; indentation depth measuring range: 0 to $10 \mu \mathrm{m}$; indentation depth readability, $0.001 \mu \mathrm{m}$; diagonal length measuring unit, optical encoder; and diagonal length display resolution, $0.1 \mu \mathrm{m}$. The principle of measurements provides three types of testing: (a) the load/load-hold test mode is used to obtain the dynamic hardness of a specimen from the total indentation depth at the end of the load-hold time, (b) the cyclic load-unload test mode. where the loading and unloading up to a certain level are repeated to observe changes in plastic deformation and elastic deformation, and (c) the load with correction-load hold mode, which is often used to observe changes in deformation in soft materials 
The low-load indentation experiments were performed with a Vickers indenter (tip angle, $136^{\circ}$ ). The maximum load was $2 \mathrm{gf}$. The loading speed used was $2.9 \times 10^{-2}$ gf s $^{-1}$ with a load-hold time of $5 \mathrm{~s}$. The indentation fracture tests were performed with a load of $150 \mathrm{gf}$, a loading speed of $1.44 \mathrm{gf} \mathrm{s}^{-1}$ and a load-hold time of $5 \mathrm{~s}$.

\subsection{The scanning scratch tester}

Scanning scralch adhesion measurements were performed by the SST-101 scanning scratch tester developed by Shimadzu in collaboration with the Kinbara Laboratory in the Engineering Department of the Tokyo University. Using the SST-101, the adhesion of thin films is evaluated by the load (critical load) where the film starts to peel by scratching with a hard stylus. The friction properties can also be measured.

The adhesion strength is an important mechanical property in thin-film technology. Characterization of the adhesion strength by the scratch test devices is often used in the hard coating industry. The main units of the SST-101 are: a loading unit, a sample stage, an optical monitor and a data processing unit connected to a personal computer. The SST-101 provides a magnetloaded type cartridge, as shown in Fig. 3. During the experiments the cartridge vibrates horizontally $\left(X_{\mathrm{o}}\right.$ $\cos (\omega t)$ above the surface of the specimen, while a load $W$ is applied to the specimen. As a result, and simultaneous with the above operation, a friction $(\mu W)$ and a returning (opposite) force $\left(k_{2} X\right)$ are formed. When the cartridge vibrates, the stylus is first pulled in the direction of the vibration. When the cartridge reaches the turning point of vibration, the stylus stops until the returning force of the cartridge exceeds the friction of the stylus, and the difference in movement between the cartridge and the stylus is obtained by detecting the voltage. From the voltage output obtained, properties such as adhesion, surface roughness and friction of thin films can be obtained. With increasing load applied to the specimen, peeling or fracture of the thin film will

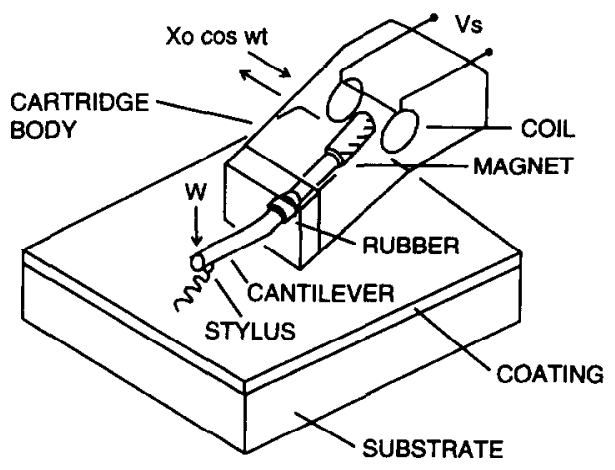

Fig. 3. Schematic view of the cartridge of the scanning scratch tester. start. At this moment, the fractured pieces of the film cause a high frequency noise in the cartridge output signal. From the onset of this signal fluctuation, the critical load $\left(L_{\mathrm{c}}\right)$ can be obtained, which can be used as the adhesion value of the thin film.

The major specifications of the SST-101 are: stylus tip radius, $10-100 \mu \mathrm{m}$; amplitude, $0-100 \mu \mathrm{m}$; frequency, $30 \mathrm{~Hz}$; load, $980 \mathrm{mN}$ maximum; down speed, 1 , 2, 5 and $10 \mu \mathrm{m} \mathrm{s}^{-1}$; and stage drive speed along the $Y$ axis, $2,5,10$ or $20 \mu \mathrm{m} \mathrm{s}^{-1}$.

The specific test parameters for the thin alumina films were: stylus tip radius, $25 \mu \mathrm{m}$; amplitude, $50 \mu \mathrm{m}$; down speed, $1 \mu \mathrm{m} \mathrm{s}^{-1}$; and stage drive speed along the $Y$ axis, $20 \mu \mathrm{m} \mathrm{s}^{-1}$.

\section{Results}

\subsection{Micro-indentation tests}

Indentation tests were performed on amorphous alumina films deposited on AISI 304 at low (LP-MOCVD) and atmospheric pressure (AP-MOCVD). The effects of growth rate, film thickness and deposition temperature were studied in relation to the load-displacement curves and indentation fracture behaviour.

\subsection{1. $\mathrm{Al}_{2} \mathrm{O}_{3}$ films by low-pressure $\mathrm{MOCVD}$}

For alumina films deposited at low pressure and high temperatures, the load-displacement curves show numerous discontinuities, especially at low loads and low loading speeds. At higher loads and loading speeds this effect was hardly observed, probably owing to the lower sensitivity of the micro-hardness tester with increasing loading speed and the larger contribution of the material properties of the underlying substrate. In Fig. 4, representative load-displacement curves are shown as a function of the deposition temperature of alumina films. It was found earlier [21] that unusual load-displacement curves, in this case discontinuities by $\mathrm{z}$ shaped interruptions, were related to crack formation. Regarding our indentation experiments, no other indentation loading failure events occurred, such as a load plateau or abrupt drops in load as found by Samandi et al. [10] and $\mathrm{Wu}$ et al. $[17,18]$, respectively. No clear difference between the different loading patterns of the curves from the specimens with different growth rate and film thickness was found.

From the indentation tests it was clear that the composite hardness increases with increasing deposition temperature. This effect was also observed with increasing film thickness, where the final displacements were smaller for thicker films. Fig. 5 shows two representative load-displacement curves, corresponding to film thicknesses of 0.5 and $0.9 \mu \mathrm{m}$. There was no significant change in the hardness values of the alumina films deposited with different growth rates. 

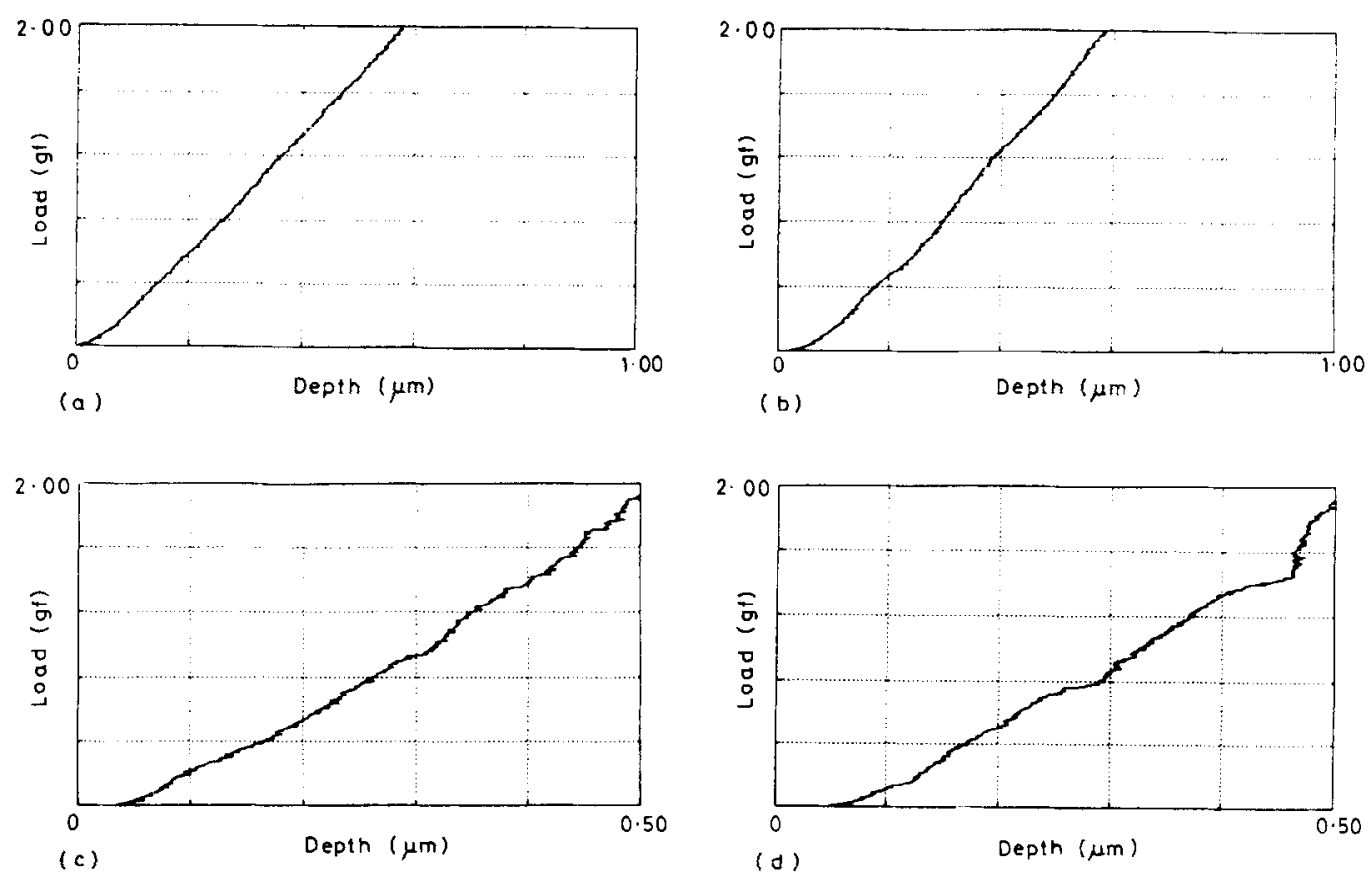

Fig. 4. Load-displacement curves of $\mathrm{Al}_{2} \mathrm{O}_{3}$ films deposited at low pressure at various temperatures: (a) $2800^{\circ} \mathrm{C}$; (b) 300 C: (c) $320{ }^{\circ} \mathrm{C}$; (d) 340 C.
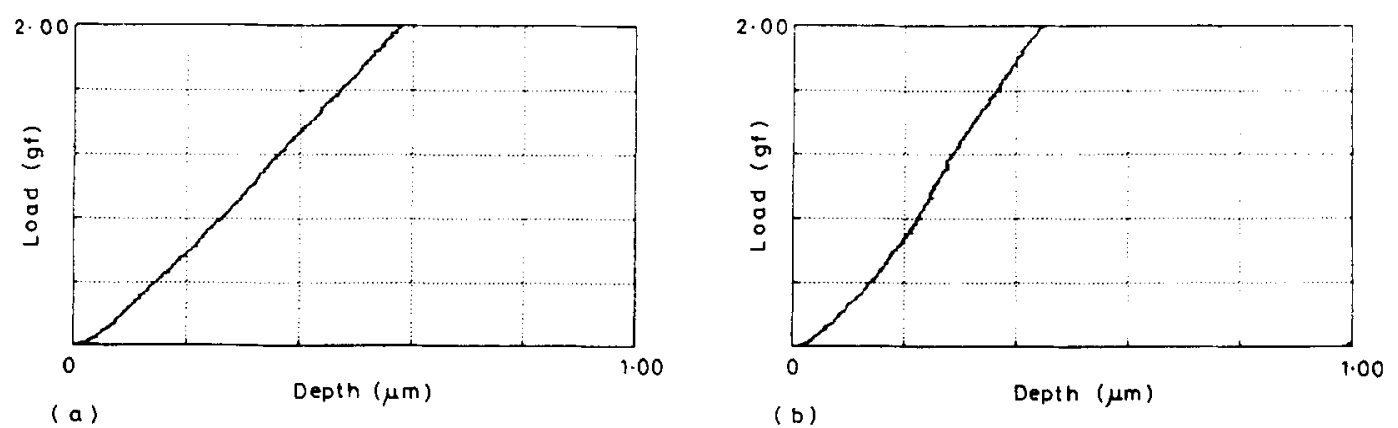

Fig. 5. Load-displacement curves for $\mathrm{Al}_{2} \mathrm{O}_{3}$ films of different thickness deposited at low pressure: (a) $0.47 \mu \mathrm{m}$ thick: (b) $0.94 \mu \mathrm{m}$ thick.

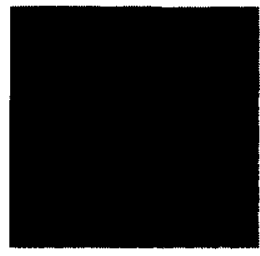

(a)

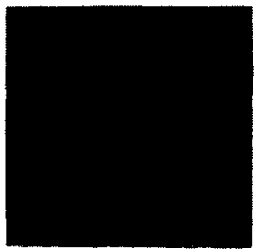

(b)

Fig. 3. Micrographs of impressions on $\mathrm{Al}_{2} \mathrm{O}_{3}$ films deposited at low pressure with thicknesses of (a) $0.47 \mu \mathrm{m}$ and (b) $0.07 \mu \mathrm{m}$.

The indentation fracture tests show that no spalling occurred of the films deposited between 280 and $360{ }^{\circ} \mathrm{C}$. Only small cracks at the edge and within the impression were formed, the number being slightly reduced with increasing deposition temperature. The fracture pattern of alumina films shows generally circumferential cracks around the impression, which is more pronounced with increasing film thickness. In Figs. 6(a) and 6(b), micrographs are shown of the impression on $\mathrm{Al}_{2} \mathrm{O}_{3}$ films with thicknesses of 0.47 and $0.07 \mu \mathrm{m}$. The effect of the growth rate on the indentation fracture was also studied, and reducing the growth rate of the alumina films showed no significant changes in the cracking behaviour of the alumina films.

\subsection{2. $\mathrm{Al}_{2} \mathrm{O}_{3}$ films by atmospheric-pressure $\mathrm{MOCVD}$}

From the indentation experiments performed on alumina films coated on AISI 304 at atmospheric pressure, no clear deviation from the ideal behaviour was found between the load-displacement curves as a function of the deposition temperature, film thickness and growth rate. On the other hand, especially at low deposition temperatures, the composite hardness increased with increasing deposition temperature. Furthermore, the hardness of the composite also increased with increas- 

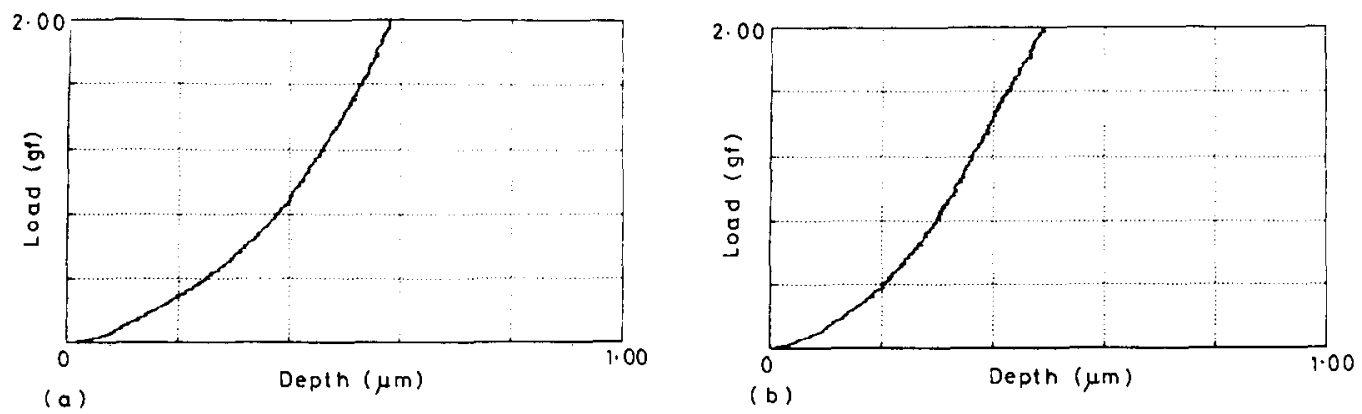

Fig. 7. Load-displacement curves of $\mathrm{Al}_{2} \mathrm{O}_{3}$ films deposited at atmospheric pressure at different temperatures: (a) 270 " $\mathrm{C}$; (b) 330 C.
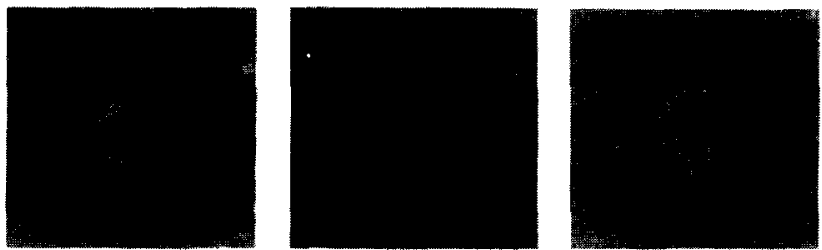

(a)

(b)

(c)

Fig. 8. Surface morphology after indentation of $\mathrm{Al}_{2} \mathrm{O}_{3}$ films deposited at atmospheric pressure at different temperatures: (a) $270{ }^{\circ} \mathrm{C}$ : (b) 330 ${ }^{\circ} \mathrm{C}$; (c) $400{ }^{\circ} \mathrm{C}$.

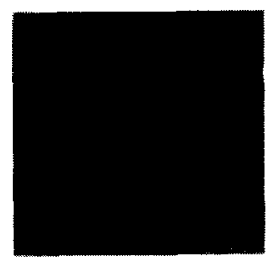

(a)

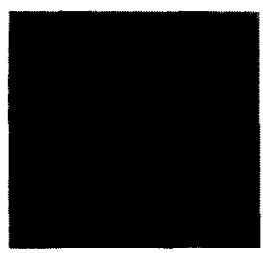

(c)

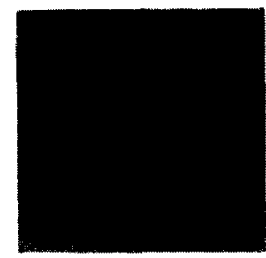

(b)

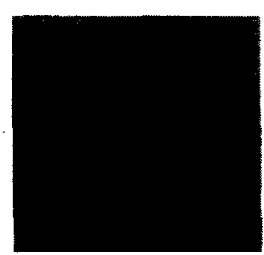

(d)
Fig. 9. Surface morphology after indentation of the $\mathrm{Al}_{2} \mathrm{O}_{3}$ films of different thicknesses deposited at atmospheric pressure: (a) $0.99 \mu \mathrm{m}$ thick; (b) $0.69 \mu \mathrm{m}$ thick; (c) $0.49 \mu \mathrm{m}$ thick; (d) $0.25 \mu \mathrm{m}$ thick.

ing film thickness (deposition temperature, $330{ }^{\circ} \mathrm{C}$ ). Figs. 7(a) and 7(b) show the load-displacement curves for the composites with alumina films, deposited at 270 and $330^{\circ} \mathrm{C}$.

The indentation fracture tests show that cracking and spalling of the alumina films decreased with increasing deposition temperature. The amount and the average length of the radial cracks were reduced with increasing deposition temperature. At deposition temperatures as low as $270{ }^{\circ} \mathrm{C}$, the film was partly spalled away. No tendency to form circumferential cracks was observed for these alumina films. Fig. 8 shows the surface mor- phology as a function of the deposition temperature of the $\mathrm{Al}_{2} \mathrm{O}_{3} / \mathrm{AISI} 304$ specimens after indentation.

Experiments with alumina films deposited at $330{ }^{\circ} \mathrm{C}$ with varying film thickness reveal increased spalling and cracking with increasing film thickness. $\mathrm{Al}_{2} \mathrm{O}_{3}$ films with a thickness of $1.0 \mu \mathrm{m}$ show many radial cracks, with local delamination of the film. For films with a thickness of about $0.1 \mu \mathrm{m}$, almost no cracks and/or spalling of the film are observed. In Fig. 9, pictures are shown of the indentation tests on $\mathrm{Al}_{2} \mathrm{O}_{3}$ films of varying thickness. Reducing the growth rate of the alumina films showed a slight reduction in the cracking and spalling of the alumina film.

\subsection{Scratch adhesion tests}

Fig. 10 shows a schematic illustration of the scratch adhesion test results. In Fig. 10(a), at position A, the output voltage rate increases continuously with increasing load. At these low loads the coating deforms with the substrate and the friction of the stylus increases with increasing load, see also Fig. 10(b). The delay in

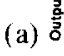

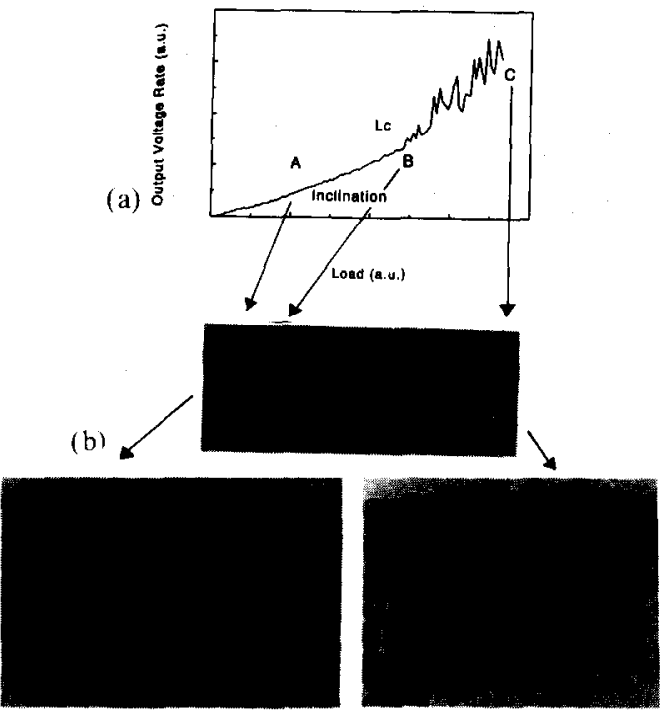

(c)

(d)

Fig. 10. Schematic illustration of the scratch adhesion test results. 
the stylus movement relative to the cartridge movement becomes larger, resulting in an increasing cartridge output rate. In this stage, no delamination occurs. From the inclination of the output signal curve, the coefficient of friction between the stylus and the specimen material can be calculated. Next, from this initial part of the curve, the surface roughness can also be measured. The higher the roughness, the more scatteriirg of the output signal during the initial stage of the test. Calculating the coefficient of friction and surface roughness is beyond the scope of this paper. Al position $\mathrm{B}$, the output voltage rate suddenly increases, indicating crack formation and/or delamination. The corresponding load is called the critical load $\left(L_{\mathrm{c}}\right)$. Fig. 10(c) shows the initiation of delamination of the alumina film, where the film is peeled locally from the underlying substrate.
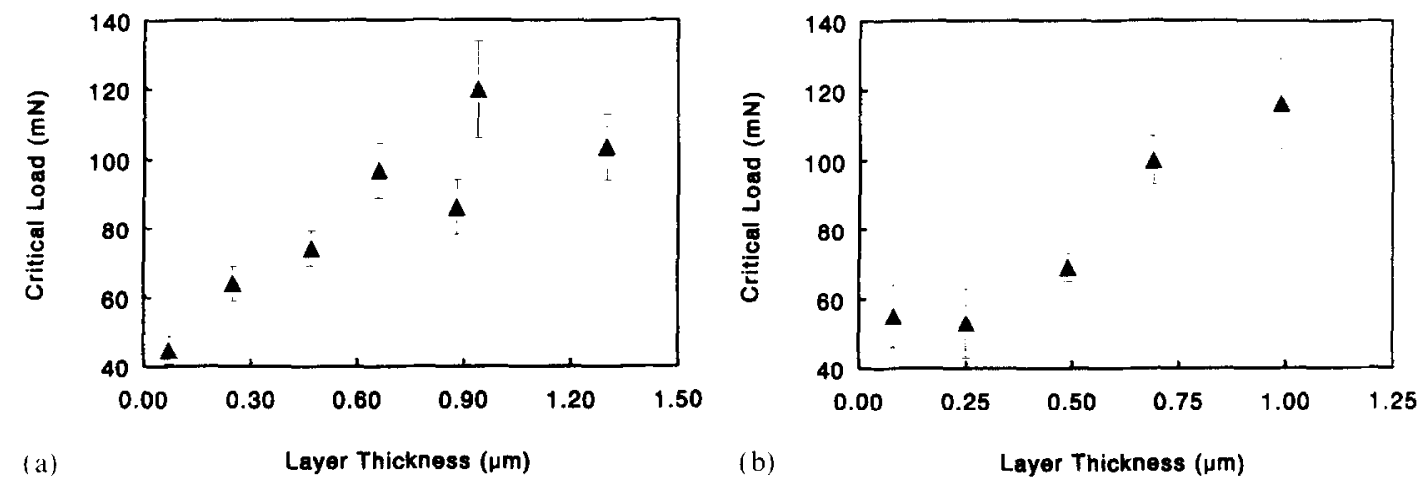

(b)

At the end of the scratch test, at position $C$, no adhesion of the film occurs any more. The film is fully spalled from the substrate, as shown in Fig. 10(d). (Figs. 10(b) $-10(d)$ are taken from the scratch on an (AP-MOCVD) alumina film with a film thickness of 0.5 $\mu \mathrm{m}$ and deposited at standard conditions (see also Section 2 above) with a deposition temperature of 300 C).

In Figs. $11(\mathrm{a})$ and $11(\mathrm{~b})$, the critical loads $\left(L_{\mathrm{c}}\right)$ are shown as a function of the coating thickness for alumina films deposited at low and atmospheric pressures. The critical loads were obtained from the scratch loading curves corresponding to the position of the first sudden increase of the output voltage. For each sample, $10-15$ scratches were made so that the average and the standard deviation of the measurements could be calculated. The results show that the critical load for both
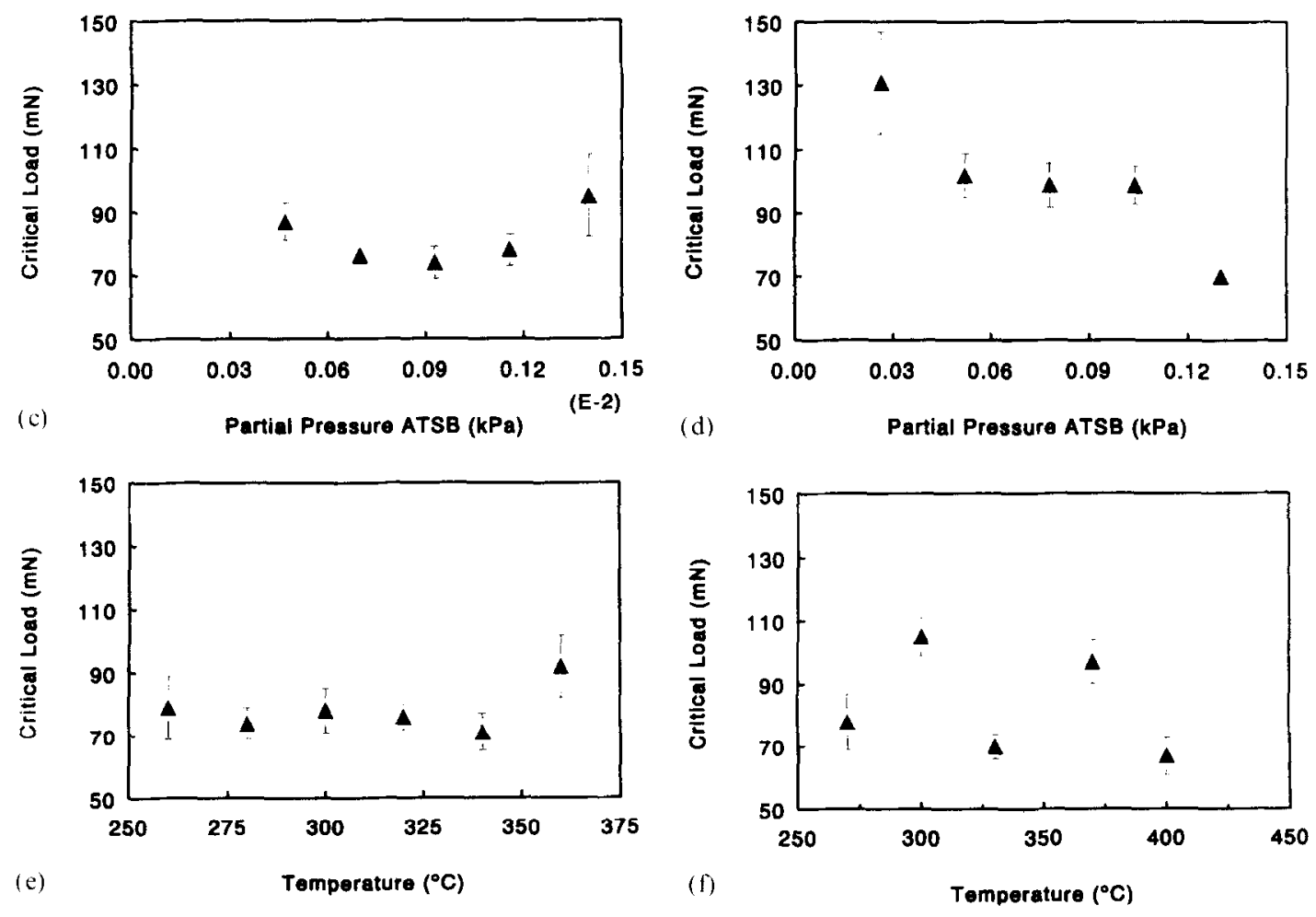

Fig. 11. Critical loads for alumina films deposited at low pressure ((a),(c).(e)) and atmospheric pressure ((b),(d),(f)) as a function of the layer thickness ((a),(b)), ATSB concentration ((c).(d)), and deposition temperature ((e),(l)). 


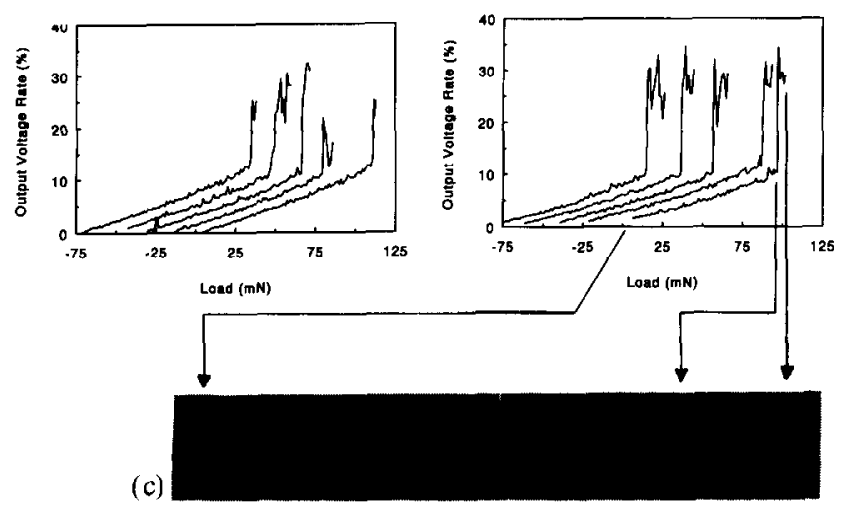

Fig. 12. Plots of output voltage vs. Ioad for $\mathrm{Al}_{2} \mathrm{O}_{3}$ tilms deposited at atmospheric pressure at (a) $300^{\circ} \mathrm{C}\left(0.5 \mu \mathrm{m}\right.$ thick) and (b) $330{ }^{\circ} \mathrm{C}(0.7$ $\mu \mathrm{m}$ thick).

coatings, deposited at low pressure as well as at atmospheric pressure, increased with increasing coating thickness. In this case, no difference occurs between the critical loads of the coatings deposited at reduced and atmospheric pressures.

The measured critical loads as a function of the partial pressure of ATSB (correlated to the growth rate) and deposition temperature are given in Figs. 11(c)-11(d) and $11(\mathrm{e})-11(\mathrm{f})$, respectively. With increasing partial pressure of the ATSB (increasing growth rates) the critical load of AP-MOCVD reduced from 130 to almost $70 \mathrm{mN}$. The critical load of the LP-MOCVD alumina films did not significantly change with varying partial pressures of the ATSB. No effect could be found of the critical load as a function of the deposition temperature (see Figs. 11(e) and 11(f)). The averaged critical load for the alumina films $(0.5 \mu \mathrm{m})$ deposited at atmospheric pressure is about $85 \mathrm{mN}$, and for the films deposited at reduced pressure about $80 \mathrm{mN}$.

In Figs. 12(a) and 12(b) the plots (overlay graphs with zero-point shifts) are shown of the output voltage vs. load of the AP-MOCVD alumina films deposited at 300 ${ }^{\circ} \mathrm{C}(0.5 \mu \mathrm{m})$ and $330^{\circ} \mathrm{C}(0.7 \mu \mathrm{m})$, respectively. Fig. 12 (c) shows the scratch morphology of the $0.5 \mu \mathrm{m}$ coated alumina film (deposition temperature, $300^{\circ} \mathrm{C}$ ) correlated to the delamination pattern and the shape of the scratch loading curve in Fig. 12(a). The films were produced at standard conditions as described in Section 2.

\section{Discussion}

Besides the use of hardness testers to calculate the resistance of a material to plastic deformation [27], these can also be used to study the indentation fracture phenomena in relation to the corresponding load-displacement curves $[10,21,28]$. In our case, where thin films are used, the hardness measurements imply the use of low loads, because otherwise the material proper- ties of the underlying substrate will contribute to the overall hardness values. It has been shown that the indentation depth may not exceed one-tenth of the film thickness [22]. Therefore, the Shimadzu hardness tester (DUH-200) is not suitable for determining the real hardness values of alumina films $0.1-2.0 \mu \mathrm{m}$ thick. So the hardness values obtained from the DUH-200 are not only related to the hardness of the thin alumina films, but also to the hardness of the substrate, which is also expressed as the composite hardness of the specimen. In order to calculate the film hardness from the substrate and composite hardness, many algorithms have been developed $[8,9,23,24]$. For example, Thomas [9] reported that an empirical relationship between the composite hardness $H_{\mathrm{c}}$ and the indentation diagonal can be derived as follows:

$H_{\mathrm{c}}=A+\frac{B}{d}$

where $A$ and $B$ are constants; $A$ can be interpreted as representing the hardness of the substrate at high loads.

From the indentation experiments, it was found that the composite hardness of the specimens (atmosphericand reduced-pressure MOCVD) increases with increasing deposition temperature and film thickness (constant load and load speed). Considering that the substrate properties were not influenced by the deposition experiments, it may be proposed that the hardness of the coating increases with increasing deposition temperature. It is of course well known that, with increasing film thickness, the contribution of the substrate hardness to the composite hardness decreases.

It was found before [29] that the films contain alumina and boehmite $(\mathrm{AlO}(\mathrm{OH}))$. X-Ray photoelectron spectroscopy measurements revealed that the amount of boehmite decreased with increasing temperature. This was confirmed by Fourier transform infrared spectroscopy, showing that the $\mathrm{OH}$ peak decreased with increasing deposition temperature. Probably, the higher the deposition temperature, the lower the amount of $\mathrm{OH}$ groups and thus the higher the hardness of the film. Quantification of the hardness of these thin films, using several algorithms that relate to the film hardness, substrate hardness and composite hardness, by the Shimadzu DUH-200, was performed earlier [30,31]. From the results it was shown that the load-displacement curves contain more irregularities with increasing deposition temperature. The higher the deposition temperature, the higher the deviation from the ideal behaviour. This effect was not observed in the load-displacement curves for the films grown at different growth rates or at different thicknesses. The discontinuity can be related to the formation of cracks $[10,21,28]$. For example, Samandi et al. [10] found at intermediate loads a sharp change in the slope of the loading curve due to film fracture. It was not possible to observe the indentation 
process in situ. After unloading, the indentation could be studied.

Thomas [8] already mentioned that poor adhesion of the coating to the substrate can result in spalling and delamination during the indentation tests. This can be used as a qualitative adhesion test for coated components. The irregularities probably have been attributed to the formation and growth of cracks. The length of the radial and lateral cracks can be used to evaluate the fracture toughness of the films and film/substrate interfaces [21]. Mehrotra and Quinto [32] and Chiang et al. [33] used a semi-analytical relationship between the fracture toughness of the coating/substrate interface and the crack length, as follows:

$c^{2}=\frac{\alpha_{1} t^{3 / 2} H^{1 / 2}\left(1-\frac{P_{\mathrm{cr}}}{P}\right) P^{1 / 2}}{K_{\mathrm{Ic}, \text { interface }}}$

where $c$ is the measured lateral crack length, $P$ is the applied load, $P_{\text {cr }}$ is the critical load, $\alpha_{1}$ is a numerical constant, $t$ is the film thickness, $H$ is the mean hardness, and $K_{\mathrm{Ic}}$ is the fracture toughness of the film/substrate interface. From this equation it follows that the smaller the lateral crack length, the higher the fracture toughness of the film/substrate interface.

Again, by analogy with the fracture toughness of the film'substrate interface, the film fracture toughness can be calculated [34] from the relationship

$K_{\mathrm{Ic}}=0.129\left(\frac{H a^{0.5}}{\phi}\right)\left(\frac{E \phi}{H}\right)^{0.4}\left(\frac{L}{a}\right)^{-3 / 2}$

where $H$ is the film hardness, $a$ is half the indentation diagonal, $\phi$ is a numerical constant, $E$ is the Young's modulus, and $L$ is the radial crack length.

In order to obtain the critical load corresponding to the initiation of crack formation, it is recommended to extend the micro-indentation system with acoustic emission measurements, implying that the load-displacement can be followed continuously relating to fracture and plastic deformation of the materials. Crack growth, delamination and dislocation glides are related to sudden changes in stress. This change in energy will be sufficiently large and rapid that ultrasonic vibrations are generated which can be monitored $[16,35]$.

The indentation results of the AP-MOCVD alumina films show that the averaged radial crack length increases with increasing film thickness and decreasing deposition temperature. By analogy, the amount of delamination also increases, which may be indicative of a worse adherence between the film and the substrate. This means that, relating to Eqs. (2) and (3), the fracture toughness of both the film and the film/substrate interface increases with increasing deposition temperature and reducing film thickness. This corresponds well with earlier results [36], where the alumina films delaminate from the substrate after reaching a critical thickness. Owing to an increased thickness, the stress near the interface increases, resulting in a lower fracture toughness of the film/substrate interface. Analogous phenomena were also found with LPMOCVD alumina films, where the number of cracks increases with increasing film thickness. From the fact that in this case circumferential cracks were formed, it follows that the stress distribution differs here from the AP-MOCVD.

Next to the qualitative studies on film fracture performed by the micro-indentation tester, the adhesion of the thin alumina films was evaluated by the scanning scratch tester. The adhesion of the films was based on the critical load causing damage to the coating/substrate system. Studying the several failure modes during the scratch tests, as documented by Burnett and Rickerby [37], is beyond the scope of this paper. For alumina films, deposited at both low and atmospheric pressures, it was found that, with an increase in film thickness, the critical load also increases. Steinmann et al. [16] and Hummer and Perry [38] reported that the extent and mode of coating/substrate deformation caused by the stylus is mainly determined by the substrate deformation. The shear force is transmitted through the film by elastic and/or plastic deformation. Therefore, it is reasonable to understand that an increased film thickness requires a higher load to obtain the same critical deformation for film cracking. This fracture behaviour is in contrast with the fracture behaviour of the film relating to the indentation tests, where the cracks and delamination were more pronounced with increasing film thickness. Probably, the influence of the thickness of the film dominates the increased stress incorporated near the film/substrate interface. Therefore, the indentation fracture and the scratch adhesion failure are probably based on different mechanisms.

For the same reason, it is clear that the critical load increases with increasing hardness of the underlying substrate. These phenomena were also found by others [39-41]. Next to the hardness of the substrate, other material properties may also influence the critical load. For example, Tosa et al: [42] found that alumina films adhered well on alloys where $\mathrm{TiC}$ had been precipitated at the interface between the film and the alloy. It was suggested that the mechanism of adherence improvement was caused by $\mathrm{TiC}$ precipitation, where the $\mathrm{TiC}$ had penetrated into the alumina film (anchoring effect) forming $\mathrm{Al}-\mathrm{O}-\mathrm{Ti}$ bondings. Furthermore, it was also found that the adherence can be influenced negatively by precipitated graphite alone. The local volume expansion of precipitated graphite can push up the alumina film, causing cracking and/or delamination. This is in contrast with the conclusions of Helmersson et al. [43], who reported that the carbide content in the steel increases the adhesion. This is thus only true when 
metal-carbide-forming elements are present in the alloy, for example, $\mathrm{Ti}$ or $\mathrm{W}$. Also sulphur segregation degrades the adherence between the alumina film and the substrate.

Furthermore, it is well known that the amount of internal stress also affects the critical load. The internal stress, caused for example by the difference between the thermal expansion coefficients, atomic interaction between the film and substrate, or incorporation of foreign elements, will alter the deformation behaviour beneath the scratch stylus. Roth et al. [44] reported that coatings show better adhesion with increasing compressive stress. It was suggested that a tensile load component parallel to the interface seems to be responsible for the adhesive failure of the coatings. Therefore, coatings show better adhesion with increasing compressive stress. This means that a superposition of the compressive stress on the tensile stress, the latter as a result of the scratch test, may result in improved adhesion behaviour of the alumina film [44].

In our case, the substrate material was not altered. Only the MOCVD process parameters were changed to obtain well-adhering and protective alumina films. With decreasing growth rates the critical load increases, indicating better adhesion of the alumina film. Probably, due to the lower growth rate, a smaller tensile or a higher compressive stress is present near the film/substrate interface. Therefore, a higher tensile stress is needed to reach the critical load starting film fracture. This was only found for the alumina films deposited at atmospheric pressure. The reduction of growth rates at low pressure, which are already much lower than at atmospheric pressure, did not have any influence on the amount of stress near the interface. For alumina films, deposited at both low and atmospheric pressures, no relation was found between the critical load and the deposition temperature. As already mentioned, the hardness of the composite slightly increases with increasing deposition temperature. This means that, if the material properties of the underlying material were not affected, the film hardness increases with increasing deposition temperature. It is therefore expected that a higher load is needed to obtain a critical deformation at the film/substrate interface to start fracture. Probably, owing to lower compressive stress or higher tensile stress incorporated in the film, the effect of increasing hardness on the critical load was cancelled out. The best-adhering alumina film can be obtained at low growth rates; this means at low pressures, or with low ATSB concentrations at atmospheric pressure. The effect of the deposition temperature was negligible.

In spite of the fact that the scratch test and indentation test involve different mechanisms on coating failure, it can be concluded that alumina films deposited at low growth rates and high deposition temperatures show the best mechanical properties. The fracture toughness of the film and of the film/substrate interface were increased, as well as the adherence between the film and the substrate.

\section{Conclusions}

This study describes the indentation and scratch adhesion tests for evaluating the mechanical properties of thin alumina films. The results from the indentation tests, the load-displacement curves and the optical microscopic pictures of the surface morphology after indentation are related to lateral and radial crack formation. In order to quantify the fracture toughness of the film and of the film/substrate interface, the critical load for crack initiation should also be determined. Probably, acoustic emission measurements can give additional information. In addition to the indentation tests, the scanning scratch tester offers a practical method to study the adhesion of thin films, based on measuring the critical load for film spalling and/or delamination.

From the indentation and scratch tests it was found that thin alumina films show the best mechanical properties, regarding fracture toughness of the film and film/substrate interface, and the adhesion to the substrate, when deposited at low growth rates and high deposition temperatures.

\section{Acknowledgment}

This research was supported by the Innovative Research Program on Technical Ceramics (IOP-TK) with the financial aid of the Dutch Ministry of Economic Affairs.

\section{References}

[1] P. Kofstad, High Temperature Corrosion, Elsevier, London and New York, 1988.

[2] M. Ohring, The Materials Science of Thin Films, Academic Press, London, 1992.

[3] P.F. Tortorelli and J.R. Keiser, Scripta Metall. Mater., 25 (1991) 2339

[4] P.F. Tortorelli, J.R. Keiser, K.R. Willson and W.C. Oliver, in M.J. Bennett and G.W. Lorimer (eds.), Microscopy of Oxidation, Proc. Ist Int. Conf., University of Cambridge, UK, 26-28 March, 1990.

[5] F. Ramos and M.T. Vieira, Mater. Manuf. Proc., 7(2) (1992) 251 .

[6] M.F. Doerner and W.D. Nix, J. Mater. Res., 1(4) (1986) 601.

[7] W.C. Oliver and G.M. Pharr, J. Mater. Res., 7(6) (1992) 1564

[8] B. Jönsson and S. Hogmark, Thin Solid Films, 114 (1984) 269.

[9] A. Thomas, Surf. Eng., 3(2) (1987) 117.

[10] M. Samandi, T.J. Bell and M.V. Swain, in W.D. Nix, J.C. Bravman, E. Arzt and L. Ben Freund (eds.), MRS Symp. Proc., 239, Materials Research Society, Pittsburgh, PA, 1991, p. 355.

[11] T.W. Wu, R.A. Burn, M.M. Chen and P.S. Alexopoulos, Mat. Soc. Symp. Proc., $130(1989) 117$ 
[12] B.D. Fabes and W.C. Oliver, in M.F. Doerner, W.C. Oliver, G.M. Pharr and F.R. Brotzen (eds.), MRS Sump. Proc., 188, Materials Research Society, Pittsburgh, PA, 1990, p. 127.

[13] K.D. Cornett, B.D. Fabes and W.C. Oliver, in M.F. Doerner, W C. Oliver, G.M. Pharr and F.R. Brotzen (eds.), MRS Symp. Proc.. 188. Materials Research Society, Pittsburgh, PA, 1990, p. 133.

[14] M.A. Korhonen, W.R. LaFontaine, C.A. Paszkiet, R.D. Black ard C.Y. Li, in M.F. Doerner, W.C. Oliver, G.M. Pharr and F.R. Brotzen (eds.), MRS Symp. Proc., 188, Materials Research Sc ciety. Pittsburgh, PA, 1990, p. 159.

[15] A J. Perry, Thin Solid Films, 107 (1983) 167.

[16] PA. Steinmann, Y. Tardy and H.E. Hintermann, Thin Solid Films. 154 (1987) 333

[17] T W. Wu, in M.F. Doerner, W.C. Oliver, G.M. Pharr and F.R. B otzen (eds.), MRS Symp. Proc., 188, Materials Research Siciety, Pittsburgh, PA, 1990, p. 191.

[18] T W. Wu. A.L. Shull and J. Lin, in M.F. Doerner, W.C. Oliver, G.M. Pharr and F.R. Brotzen (eds.), MRS Symp. Proc., 188. Materials Research Society, Pittsburgh, PA, 1990, p. 207.

[19] P.J. Burnetl and S. Rickerby. Thin Solid Films, 148 (1987) 41.

[20] P J. Burnett and S. Rickerby. Thin Solid Films, 148 (1987) 51.

[21] B N. Lucas, W.C. Oliver and J.J. Wert, in M.F. Doerner, W.C. Oliver, G.M. Pharr and F.R. Brotzen (eds.), MRS Symp. Proc., I.8. Materials Research Society, Pittsburgh, PA, 1990, p. 262.

[22] I. Manika and J. Maniks. in W.D. Nix, J.C. Bravman, E. Arzt and L. Ben Freund (eds.), MRS Symp. Proc.. 239, Materials Research Society. Pittsburgh. PA, 1991, p. 349.

[23] H.J. Bückle, in J.W. Westbrook and H. Conrad (eds.), The $S$ icnce of Hardness Testing and its Research Applications. American Society for Metals, Metals Park, OH, 1973, p. 453.

[24] P.J. Burnett and T.F. Page, J. Mater. Sci, 19 (1984) 845.

[25] Instuction Manual for Model SST-101 Scanning Shimadzu Scratch Tester, CM227-293 (Shimadzu Corporation, Kyoto, Japan).

[26] V.A.C. Haanappel, H.D. van Corbach, T. Fransen and P.J. Ciellings. Properties of alumina films prepared by atmosphericpressure metal organic chemical vapour deposition, Surf. Coat. Technol.. in press.
[27] D. Tabor, The Hardness of Metals, Clarendon Press, Oxford, UK, 1951.

[28] E. Vancoille. J.P. Celis and J.R. Roos, Thin Solid Films, 224 (1993) 168.

[29] V.A.C. Haanappel. II.D. van Corbach. T. Fransen and P.J. Gellings, Properties of alumina films prepared by low-pressure metal organic chemical vapour deposition, submitted for publication in ??

[30] J.B. Rem, Graduate Paper, University of Twente. Netherlands, 1993.

[31] R. Hofman. The Protection of Alloys against High Temperature Corrosion by $\mathrm{SiO}_{2}$-Coatings, Ph.D. Thesis, University of Twente, Netherlands, 1993.

[32] P.K. Mehrotra and D.T. Quinto. J. Vac. Technol. A. 3(6) (1985) 2401.

[33] S.S. Chiang, D.B. Marshall and A.G. Evans. in J. Pask and A.G. Evans (eds.). Surface and Interfaces in Ceramics and Ceramic Meral Sixtems, Plenum, New York, 1981, p. 603.

[34] A.G. Evans and E.A. Charles. J. Am. Ceram. Soc.. 39(1976) 371.

[35] T.P. Weihs. C.W. Lawrence, B. Derby, C.B. Scruby and J.B. Pethica, in W.D. Nix, J.C. Bravman, E. Arzt and L. Ben Freund (eds.), MRS Symp. Proc., 239. Materials Research Society, Pittsburgh, PA. 1991, p. 361.

[36] V.A.C. Haanappel, H.D. van Corbach, T. Fransen and P.J. Gellings, Mat. Sci. Eng. A, 167 (1993) 179 (chapter 4).

[37] P.J. Burnett and D.S. Rickerby, Thin Solid Films, 154 (1987) 403.

[38] E. Hummer and A.J. Perry. Thin Solid Films. 10I (1983) 243.

[39] J. Valli, J. Vac. Sci. Technol. A, 4 (1986) 3007.

[40] P.A. Steinmann and H.E. Hintermann. I. Vac. Sci. Technol. A, 3 (1985) 2394.

[41] B. Hammer, A.J. Perry, P. Laeng and P.A. Steinmann, Thin Solid Films. 96 (1982) 45.

[42] M. Tosa, Y. Ikeda and K. Yoshihara. Thin Solid Films, 177 (1989) 107.

[43] U. Helmersson, B.O. Johansson and J.E. Sundgren, J. Vac. Sci. Technol. A. 3 (1985) 308.

[44] Th. Roth, K.H. Kloos and E. Broszeit, Thin Solid Films, 153 (1987) 123 . 